\title{
Os Adjetivos Exclusivamente Pré-Dominais do Português
}

The Exclusively Prenominal Adjectives in Portuguese

Cristina de Souza Prim*

Resumo: Os adjetivos exclusivamente pré-nominais do português, ou mesmo de outras línguas românicas, são tratados en passant pela literatura. Pouco se sabe sobre suas propriedades e praticamente não há explicação do por que de sua existência. Este trabalho busca dar alguns passos para o entendimento dessas questões. As propriedades mencionadas pela literatura, de modo geral, se confundem com propriedades de adjetivos de posicionamento fixo ou adjetivos que podem ser prenominalizados. Após discussão de dados, mostramos que duas propriedades se destacam, que é o fato de os adjetivos exclusivamente pré-nominais não ocorrerem em NPs, mas apenas em DPs do português - o que mostra que estes adjetivos possivelmente são gerados numa posição mais alta que o nome -, e que seu significado é independente do nome que o acompanha, ou seja, que estes adjetivos não são selecionados pelo nome, mas, ao contrário, o selecionam sintaticamente. Estas distinções nos dizem muito ainda sobre os demais adjetivos e acabam indiretamente apresentando argumentos a favor da adjunção à direita para os demais adjetivos.

Palavras-chave: Adjetivos exclusivamente pré-nominais. Adjetivos do português. Adjetivos núcleos.

* Doutora em Linguística pela Universidade Estadual de Campinas (2015). Professora na Universidade do Estado de Santa Catarina (UDESC). Contato: cristinaprim@gmail.com 
Abstract: The exclusively prenominal adjectives in Portuguese, or even in other romance languages, are treated superficially in the literature about adjectives. We don't know much about these adjectives, their properties and why they exist. This paper seeks to take a few steps forward in this discussion. The properties mentioned currently in literature are, actually, a confusion between properties of fixed position adjectives and prenominal adjectives in general. After discussing data, we show two salient properties: exclusively prenominal adjectives do not occur in NP in Portuguese, but just in DPs (and it evidences that they are generated in a higher position of the structure); the meaning of these adjectives are independent from the noun (which means that these adjectives are not selected by the noun, but they syntactically select the noun instead). These distinctions indirectly show arguments in favor of the adjunction of other adjectives on the right side.

Keywords: Exclusively prenominal adjectives. Adjectives in Portuguese. Adjectives as heads.

\section{Para Dar Início à Discussão...}

Um ponto ainda pouco compreendido pela literatura sobre adjetivos é relacionado à obrigatoriedade de antepor ao nome certos adjetivos como mero, suposto, pretenso.

(1) a. Um mero problema

b. *Um problema mero

a. O suposto assassino

b. $* \mathrm{O}$ assassino suposto

O português é uma língua que posiciona seus adjetivos mais comumente na posição pós-nominal. Muitos adjetivos, inclusive, só ocorrem nesta posição posposta ao nome; e há, ainda, outros que têm seu posicionamento variável. Explicar a posposição do adjetivo é objetivo de muitos trabalhos, como os de Bernstein (1993), Crisma (1990, 1993), Bosque e Picallo (1996), e mais recentemente, Cinque (2010). Mas o fato é que estes trabalhos pouco têm a dizer sobre os adjetivos exclusivamente pré-nominais das línguas românicas. 
Possivelmente, dentre os trabalhos mencionados, o que se debruça com mais propriedade sobre estes adjetivos seja Bernstein (1993). Nos demais trabalhos citados, de modo geral os autores apontam apenas que estes adjetivos devem estar numa posição mais alta que o nome, de modo que o nome não possa mover-se sobre o adjetivo. O que, em nível sintático, impediria este movimento não está claro. Como Bernstein propõe uma solução para este problema, vale detalhar sua proposta.

\section{Literatura Sobre os Adjetivos Exclusivamente Pré-Nominais: Bernstein (1993)}

Bernstein (1993) defende que todos os adjetivos são gerados à esquerda do nome. Assim, a posição pós-nominal dos adjetivos é derivada via movimento do nome (Hipótese de Movimento de Núcleo - $\mathrm{HMC}^{1}$ ) sobre os adjetivos, que são gerados na posição pré-nominal. O movimento do nome, segundo esta proposta, ocorre por fatores independentes ao adjetivo, e o posposicionamento deste, portanto, é consequência de um movimento que o nome deve fazer: o núcleo $\mathrm{N}$ se move para buscar os traços de número.

Para a autora, o fato de alguns adjetivos serem exclusivamente pré-nominais nas línguas românicas, grupo linguístico em que se vê claramente a posição pós-nominal como a posição não marcada para os adjetivos, deve-se ao seu estatuto sintático de núcleo $\left(\mathrm{X}^{0}\right)^{2}$. Ela se refere aos adjetivos da classe de mero, que não podem ocorrer pospostos ao nome. Aponta que esses adjetivos apresentam uma série de propriedades que os distingue de outros adjetivos, a saber:

a) não ocorrem na posição pós-nominal, como mostra o exemplo (3);

b) não ocorrem em construções nominais elípticas, como vemos no exemplo (4);

\footnotetext{
${ }^{1}$ HMC é a sigla de Head Movement Constraint, ou Hipótese de Movimento de Núcleo. Em geral, estas teorias defendem o movimento do nome para posições mais altas na estrutura, ultrapassando a posição de adjetivos e explicando, assim, seu posposicionamento. Mais detalhes em Cinque (1993).

2 Essa proposta é baseada no trabalho de Abney (1987).
} 
c) não podem ser modificados (exemplo (5)); e

d) não aparecem em posição predicativa (exemplo (6)).

(3) $* \mathrm{O}$ acidente mero.

(4) *Vi um mero (acidente).

(5) *um muito mero acidente.

(6) *O acidente é mero.

Esses adjetivos, por serem núcleos, impedem, segundo a autora, que o nome se mova para uma posição mais alta, visto que a hipótese HMC diz que o movimento de um núcleo para outro não pode ultrapassar algum núcleo interveniente. Poderíamos nos perguntar por que o nome não se amalgama ao adjetivo núcleo. Bernstein responde que o nome só pode se amalgamar a categorias funcionais, como a flexão de número. Abaixo vemos a representação desta proposta.

(7) a. O mero acidente

b.

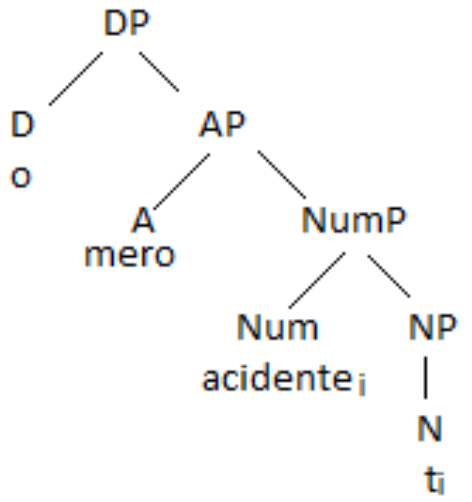

Já para os adjetivos que podem ser pré e pós-nominais, a autora postula que a diferença se deve ao movimento do nome para uma posição mais alta - o núcleo de NumP seria um lugar de pouso para os nomes movidos. Nesse caso, os adjetivos seriam gerados tanto em SpecNP (resultando em adjetivos pós-nominais com leitura restritiva, ou seja, é o adjetivo que está 
limitando a extensão do nome) quanto em SpecNumP (neste caso, os adjetivos serão pré-nominais com leitura não restritiva, ou seja, o adjetivo só está caracterizando o nome, não o limitando). A diferença do lugar de adjunção está relacionada a diferentes interpretações que os adjetivos qualificativos têm na posição anteposta e posposta ao nome. A autora não explora DPs contendo dois adjetivos adjuntos, por isso vamos exemplificar sua proposta com DPs contendo apenas um adjetivo.

(8) a. O inocente menino

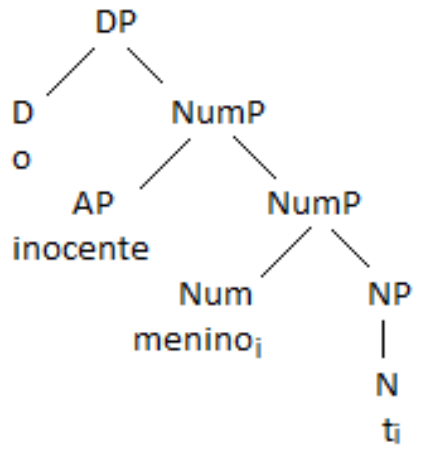

b. O menino inocente

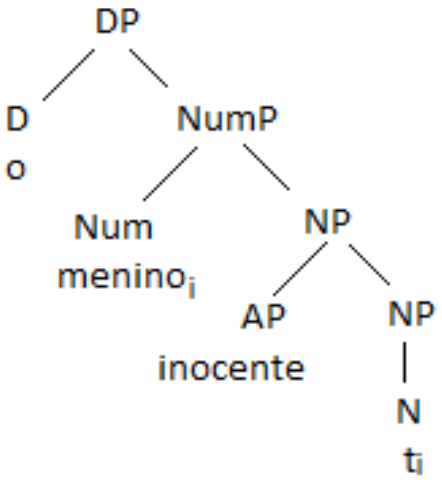

A autora também defende que há adjetivos exibindo padrão misto, como é o caso dos adjetivos estruturalmente ambíguos, que aparecem nas duas posições, mas que não se distinguem pela interpretação restritiva/não 
restritiva, e sim que apresentam diferenças significativas de interpretação, como é o caso dos adjetivos novo, simples, certo. Estes adjetivos comportam-se como núcleo na posição pré-nominal e como adjunto (que ocupam SpecNP) na posição pós-nominal.

Um problema que esta proposta enfrenta é que não se espera encontrar nenhum adjetivo mais alto que um destes adjetivos núcleos, pois violaria HMC, mas isso de fato pode ocorrer: os adjetivos meio e mero são exclusivamente pré-nominais, mas os adjetivos requerido e provável, que podem ocupar tanto a posição anteposta como a posição posposta ao nome, ocorrem numa posição mais alta que a do adjetivo núcleo. A teoria de Bernstein prevê que requerido e provável possam ser pré-nominais (são gerados nesta posição) ou pós-nominais (movimento de $\mathrm{N}$ para NumP). Mas como a autora não assume movimento de adjetivos, não há como explicar as ordens encontradas em (9b) e (10b), em que estes adjetivos, que podem ser pré ou pós-nominais, ocupam uma posição mais alta que adjetivos exclusivamente pré-nominais.

(9) a. O meio litro requerido de óleo

b. O requerido meio litro de óleo

(10) a. O mero aviso provável dos responsáveis

b. O provável mero aviso dos responsáveis

O segundo problema que apontamos para a proposta de Bernstein é que as características que definem a classe dos exclusivamente pré-nominais não estão bem delimitadas. Um adjetivo como nuclear, em um físico nuclear, também não aceita a posição predicativa, nem modificação, nem ocorre em construções nominais elípticas, ainda que este adjetivo seja exclusivamente pós-nominal em português, e quiçá em todas as línguas românicas.

(11) *O físico é nuclear.

(12) *Um físico muito nuclear

(13) *Um nuclear

Outro problema desta proposta é que, em Português Brasileiro (doravante $\mathrm{PB}$ ), temos razões para crer que número é morfossintaticamente 
especificado no Determinante, e não no Nome, e assim este movimento do nome para Num perde força explicativa.
a. As onda
b. *A ondas

Por conta disso, há autores, como Menuzzi (1994), que assumem que esta categoria para a qual o nome se move não seja Número em PB, mas Gênero. Mas a questão não se resolve: já não teríamos mais o paralelismo com as línguas germânicas, uma das grandes metas da HMC, pois, em inglês, além de os nomes não serem marcados por gênero, está bastante claro que é o Nome que morfossintaticamente carrega o número, e não o Determinante.
a. The waves
b. *Thes wave

Mesmo se olharmos somente para dentro do grupo das línguas românicas, vemos que a proposta assumida por Bernstein, de mover o nome para Número, é inconsistente. Bonet (2013) apresenta dados que evidenciam que, em Catalão, o número é especificado no Nome, dada a gramaticalidade do exemplo (16b).

a. Els bons vins

b. El bon vins ${ }^{3}$

$$
/ \mathrm{o}_{\mathrm{sg}} \text { bom }_{\mathrm{sg}} \text { vinhos }_{\mathrm{pl}} /
$$

Isto torna a proposta de movimento do Nome para Número, resultando em adjetivos pós-nominais, pouco intuitiva, mesmo se olharmos somente para as línguas românicas.

O quarto problema de valer-se da HMC para explicar o posicionamento dos adjetivos é que esta hipótese não prevê que o nome exerça qualquer papel na predição de ambiguidade do adjetivo. Contudo,

${ }^{3}$ Bonet (2013) aponta que a não realização do -s só pode ocorrer em c_c, ou seja, entre consoantes. Este fenômeno pode ocorrer no Catalão Central-Nordestino. 
pode-se perceber facilmente nos exemplos abaixo que um adjetivo pós-nominal é selecionado ${ }^{4}$ sintática e semanticamente pelo nome. A consequência desta imprevisibilidade é o vácuo explicativo que fica quando buscamos entender a falta de ambiguidade em (18b): a única interpretação possível é a de que Maria é sensual e também é administradora (leitura intersectiva); não é possível a leitura não intersectiva, ou seja, a interpretação de que "Maria administra sensualmente". A leitura não intersectiva não está disponível em (18b), mas somente em (18a).

(17) a. um físico nuclear

b.*um linguista nuclear

(18) a. Maria é uma bailarina sensual. (leitura intersectiva e não intersectiva)

b. Maria é uma administradora sensual. (somente leitura intersectiva)

Além do mais, estas propostas de movimento do nome parecem ignorar o fato básico de que, nas línguas românicas, os adjetivos exclusivamente pré-nominais e os exclusivamente pós-nominais ocorrem em geral mais próximos ao nome do que aqueles que podem variar de posição. Nos exemplos abaixo, os adjetivos renascentista, italiana, musical e americana são exclusivamente pós-nominais, e o adjetivo mero é exclusivamente pré-nominal. Os adjetivos que variam de posição, maravilhosa, divertida, provável, estão ocupando as posições mais distantes do nome.

(19) Uma construção renascentista italiana maravilhosa

(20) Uma comédia musical americana divertida

(21) O provável mero aviso dos responsáveis

Por fim, vamos apenas mencionar que esta proposta de que o adjetivo exclusivamente pré-nominal, por ser núcleo, bloqueia a subida do nome núcleo é facilmente contestada pela Teoria da Minimalidade Relativizada.

${ }^{4}$ Usamos o termo seleção, talvez, na falta de uma opção melhor. Vamos tratar os adjetivos pós-nominais como adjuntos neste trabalho, e na literatura costuma-se utilizar o termo seleção para argumentos. Mas vamos ver adiante que os adjetivos pós-nominais têm seu significado e sua ocorrência dependentes do nome que os antecede, e é neste sentido que utilizamos o termo seleção. 
Rizzi (1990) defende por esta teoria que o nome e o adjetivo, por serem categorias diferentes, possuem traços diferentes e, assim, mesmo sendo um núcleo, o adjetivo não poderia bloquear o movimento de $\mathrm{N}$ para uma posição mais alta, pois seus traços não seriam os mesmos contidos no nome e, desse modo, este poderia se mover sem considerar o adjetivo um bloqueio.

Vamos voltar à segunda crítica feita à teoria e à descrição feita por Bernstein. A autora apontou que os adjetivos exclusivamente pré-nominais possuem quatro propriedades: não ocorrer posposto ao nome, não ocorrer em construção nominal elíptica, não poder ser modificado e não aparecer em posição predicativa. Aparte a primeira propriedade, que é óbvia por natureza, as demais propriedades também pertencem aos adjetivos exclusivamente pós-nominais. Já citamos o caso do adjetivo nuclear (exemplos (11), (12) e (13)), mas podemos estender a todos os adjetivos classificativos e temáticos ${ }^{5}$. Vejamos outro exemplo. Em (22), vemos que um adjetivo como alemã é exclusivamente pós-nominal, dada a agramaticalidade de (22b). Mostramos em (22c) que estes adjetivos não permitem a elipse do nome; em (22d), que não ocorrem em posição predicativa; e, em (22e), que não podem ser modificados por um advérbio como muito. Este último exemplo é especialmente interessante porque conseguimos imaginar um contexto em que o exemplo seja gramatical, que é com uma leitura de adjetivo qualificativo, ou seja, a interpretação é de que a invasão foi ao modo alemão de invadir, sem necessariamente ter sido feita por alemães. Neste caso, o adjetivo já não é relacional.
a. A invasão alemã da Polônia
b. *A alemã invasão da Polônia
c. *Houve uma alemã (uma invasão alemã)
d. *A invasão foi alemã.
e. *Esta invasão muito alemã.

Além dessas propriedades, os adjetivos que ocorrem somente na

\footnotetext{
${ }^{5}$ De acordo com a classificação de Bosque e Picallo (1996), os adjetivos pós-nominais podem ser relacionais (formados por adjetivos classificativos e adjetivos temáticos) e adjetivos qualificativos. Os primeiros são exclusivamente pós-nominais; já os qualificativos podem ser pré ou pós-nominais.
} 
posição anteposta ao nome possuem outras propriedades sintáticas (mas não semânticas) bastante parecidas com as dos adjetivos exclusivamente pós-nominais: não aceitam superlativo (exemplo (23a) para pré-nominais e (24a) para pós-nominais) ou diminutivo (os exemplos (23b) e (24b)), o que mostra que não é apenas a modificação por advérbio que não ocorre, e não podem ser nominalizados (exemplos (23c) e (24c)).
a. *O supostíssimo candidato à presidência
b. $*$ O pretensinho violinista
c. *A mericidade do problema
a. $*$ O físico nuclearzíssimo.
b. ${ }^{*} \mathrm{O}$ físico nuclearzinho
c. *A nucleação do físico

Portanto, as características mencionadas por Bernstein para os adjetivos exclusivamente pré-nominais pertencem, na verdade, a todos os adjetivos que têm posicionamento fixo no português (e, possivelmente, em outras línguas românicas), tanto se obrigatoriamente pós-nominal quanto pré-nominal.

\section{Quais as Características de um Adjetivo Pré-Nominal?}

Há algumas características que possuem todos os adjetivos pré-nominais, e deve-se tê-las em mente para que não se cometam equívocos na descrição. Uma delas é que todos os adjetivos pré-nominais nunca são intersectivos ${ }^{6}-$ o que não quer dizer que sejam adverbiais, como propõe

${ }^{6}$ Com intersectividade, queremos dizer que, em um DP contendo um nome e um adjetivo, temos a interseção de dois grupos. Por exemplo, em uma flor amarela, temos a interseção do grupo das coisas que são flores com o grupo das coisas que são amarelas. Com um adjetivo pré-nominal, isto não ocorre: em um mero homem, não podemos imaginar um grupo das coisas que sejam homens e outro das que sejam meras. Todos os pré-nominais possuem este comportamento. Cinque (2010) diz que os não intersectivos têm um comportamento adverbial. Um exemplo mais claro: um atacante bom. Para a leitura não intersectiva, Cinque sugere a paráfrase como um atacante que ataca bem. Contudo, essa relação com a leitura adverbial é falha, já que não se pode parafrasear um mero homem como um homem que é meramente um homem. 
Cinque (2010). A impossibilidade da leitura intersectiva é uma característica que faz parte da posição pré-nominal, e não somente de uma classe de adjetivos que ocorre à esquerda do nome.

Outra característica de todos os adjetivos pré-nominais é não aceitar complementação e DPs com nomes nulos - os adjetivos que ocorrem neste último caso têm comportamento de pós-nominal porque possuem as mesmas leituras encontradas no adjetivo posposto ao nome. A modificação também é bastante restrita na posição pré-nominal. Os adjetivos, neste caso, não aceitam modificação por muito, ainda que alguns aceitem superlativos ou prefixação por super.

É incomum encontrar dois ou mais adjetivos antepostos ao nome simultaneamente. Diferentemente da posição pós-nominal, a ordem de dois adjetivos antepostos ao nome será necessariamente a ordem correspondente ao escopo relativo de um adjetivo sobre outro. Tomemos (25), por exemplo. No primeiro DP, temos brilhante com escopo sobre possivel substituto, o que resulta em: há um possível substituto, um em específico, que é brilhante. No segundo DP, temos possivel com escopo sobre brilhante substituto. Neste caso, temos uma pessoa que possivelmente será um brilhante substituto.

(25) a. Um brilhante possível substituto

b. Um possível brilhante substituto

(26) a. Meu verdadeiro único amigo

b. Meu único verdadeiro amigo

(27) a. A suposta velha igreja românica

b. A velha suposta igreja românica

Os adjetivos qualificativos podem preceder outro qualificativo pré-nominal se o primeiro tiver escopo sobre o segundo (cf. (25-27)). Se não puderem ser interpretados deste modo, os adjetivos devem ser coordenados (ver (28-30)). A coordenação pode se dar entre adjetivos pré-nominais de classes diferentes, como mostra (30), diferentemente do que ocorre na posição pós-nominal. Isso só garante que um não tenha escopo sobre o outro.

(28) A maravilhosa e longa jornada. 
(29) a. *a preciosa elegante bolsa (não significa preciosamente elegante)

b. A preciosa e elegante bolsa

(30) A preciosa e grande missão dada aos meninos

A coocorrência de dois pré-nominais, portanto, obedecerá sempre os interesses de escopo; a única alternativa para escapar disso é através da coordenação, ainda que sejam adjetivos de classes diferentes. Já na posição pós-nominal, a coordenação só ocorre entre adjetivos relacionais ou entre adjetivos qualificativos ${ }^{7}$. Isto mostra que o ambiente pré-nominal possui propriedades bastante distintas do pós-nominal.

Tendo em mente que as propriedades mencionadas acima não pertencem apenas aos adjetivos em questão, vejamos como diferir os adjetivos de posicionamento fixo, ou seja, os adjetivos exclusivamente pré-nominais dos exclusivamente pós-nominais.

\section{Diferenças dentre Adjetivos de Posicionamento Fixo e Características dos Exclusivamente Pré-Nominais}

Como dissemos, os adjetivos que ocorrem somente na posição anteposta ao nome possuem propriedades sintáticas bastante parecidas com as dos adjetivos exclusivamente pós-nominais. Há, contudo, diferenças consideráveis entre os adjetivos exclusivamente pré-nominais e os relacionais que nos impedem de tratá-los como uma única classe.

Uma diferença sintática, já mencionada, é a possibilidade de coordenação dos exclusivamente pós-nominais somente com outros adjetivos da mesma classe (rever nota 7); já os exclusivamente pré-nominais, como já mostramos em (30), podem ser coordenados com adjetivos qualificativos pré-nominais. Trazemos outros exemplos a seguir.

(31) O suposto e alegado desvio de conduta da instituição

(32) Visitei o suposto e tão temido umbuzeiro mal assombrado

${ }^{7}$ A coordenação de adjetivos qualificativos não pode ocorrer com um adjetivo relacional.

i. *A invasão alemã e terrível 
A segunda diferença é que os adjetivos gerados na posição pós-nominal são selecionados ${ }^{8}$ pelo nome que o antecede, diferentemente dos adjetivos exclusivamente pré-nominais. Explicamos: adjetivos como mero, pretenso e suposto, por exemplo, podem se combinar com qualquer tipo de nome, como mostram os exemplos abaixo.

(33) Um mero homem/ problema/ sentimento/ papel de carta/ arroz integral

(34) Um pretenso batuqueiro/ direito de mentir/ sindicato/ livro de histórias infantis

(35) Um suposto assassino/ solução para o problema/ separação/ livro didático

Já os adjetivos pós-nominais, qualquer que seja a classe a que pertença, têm seu significado determinado pelo nome que os acompanha e, por isso, os adjetivos que podem ocorrer com certo nome dependem do campo semântico deste. Em (36), temos o nome invasão, que não combina com adjetivos de cor, a menos que esta cor se refira a algum grupo em específico: amarelo seria gramatical, neste caso, se estivesse se referindo a orientais, mas não à cor amarela. Em (36) vemos também que os adjetivos qualificativos, que têm posicionamento variável, também sofrem esta mesma restrição: o adjetivo atenciosa também tem sua ocorrência dependente do campo semântico do nome que o acompanha; invasões não podem ser atenciosas, mas invasores sim.

(36) Uma invasão ibérica/*amarela/*integral/*muito atenciosa.

(37) O colapso mental/*assombrado/?carnívoro/*rosado.

Esta característica mostra claramente que os adjetivos exclusivamente pré-nominais têm um comportamento diferente dos outros tipos de adjetivos.

${ }^{8}$ Usamos o termo seleção, talvez, na falta de uma opção melhor. Na literatura costuma-se utilizar o termo seleção para argumentos, o que não cremos que os adjetivos sejam. Utilizamos o termo seleção neste trabalho no sentido de que os adjetivos pós-nominais têm seu significado e sua ocorrência dependentes do nome que os antecede. 
Outra característica forte destes adjetivos, e igualmente não apontada pela literatura, se apresenta nos contextos de NP. Segundo a proposta de Espinal e McNally (2011), os nomes nus podem ser tanto NPs quanto DPs. NPs, que seriam nomes contáveis nus não especificados para número e definitude, ocorrem como objeto de uma reduzida classe de predicados relacionados com as estruturas ter + NP, e têm leitura de propriedade. Não saturam, só modificam o predicado, ou seja, não ocorrem em posição argumental, e por isso não se pode substituí-los por um pronome, visto que os pronomes indicam uma descrição definida. Essa proposta segue Longobardi (1994), que defende que "uma expressão nominal é um argumento somente se é introduzido por uma categoria D. DP pode ser um argumento, NP não pode.” (LONGOBARDI, 1994, p. 628).

Os adjetivos pós-nominais são possíveis tanto em NPs (ver (38a)) quanto em DPs (ver (38b)). Já os adjetivos exclusivamente pré-nominais (como é o caso de provável) só ocorrem em DPs. Em (39), vemos a ocorrência de um adjetivo pré-nominal porque o sintagma é obrigatoriamente um DP, e a possibilidade de retomada pelo pronome comprova que não se trata de uma propriedade, mas de um indivíduo, um argumento do verbo.

(38) a. Maria usa vestido amarelo só quando suas amigas compram *ele/ *eles para ela.

b. Maria usou um vestido amarelo porque suas amigas compraram ele para ela.

(39) Maria usa provável vestido de noiva da sua irmã no Expo Noivas e Festas porque ele combina muito com ela também.

Uma teoria que postula que todos os adjetivos são gerados de forma semelhante na posição pré-nominal é incapaz de prever estas diferenças de comportamento.

Estas duas últimas características citadas, em especial, mostram um estatuto diferente para estes adjetivos. Mais à frente, apresentaremos uma proposta de estrutura para estes adjetivos. Defenderemos que, com exceção dos exclusivamente pré-nominais, todos os demais adjetivos são gerados à direita de $\mathrm{N}$, e esta proposta também é baseada nos argumentos citados 
acima - a adjunção à direita explica por que os demais adjetivos ocorrem em NP e por que têm seu significado dependente do nome que o antecede.

\section{Como Saber se um Adjetivo é Exclusivamente Pré-Nominal?}

A pergunta pode parecer óbvia, mas não é. Há certos adjetivos que possuem um significado lexical diferente na posição pré e pós-nominal, que podem deixar dúvidas se são membros desta classe ou se pertencem à classe dos qualificativos. Incluem-se na discussão adjetivos como antigo, novo, pobre, pequeno, grande, certo, bom, velho, simples. Se considerarmos que alguns destes adjetivos, ao menos, são exclusivamente pré-nominais, isto tem como consequência a necessidade de afirmar que há duas entradas lexicais para estes adjetivos, porque também ocorrem em posição pós-nominal com um significado diferente. Será o caso de se postular homonímia para todos eles? Estes adjetivos apresentam propriedades que parecem se contradizer, mas buscaremos esclarecer o que ocorre com cada um deles.

Por um lado, poderíamos dizer que pobre e certo são claramente adjetivos que só ocorrem na posição pré-nominal, porque o significado que possuem na posição pré-nominal nunca é igual ao da posição pós-nominal.

(40) a. Um pobre refugiado (que inspira compaixão)

b. Um refugiado pobre (sem recursos financeiros)

(41) a. Um certo momento (determinado, distinguível de outros similares)

b. Um momento certo (correto, combinado, preciso...)

Já bom, antigo, pequeno, novo, velho, simples e grande possuem, em alguns casos, a mesma interpretação nas posições pré e pós-nominal, a depender do nome com o qual se combinam. Vamos observar cada um desses adjetivos atentamente, porque parece haver um comportamento heterogêneo em uma lista de pouquíssimos adjetivos.

Em geral, o adjetivo bom no português possui somente interpretação bom como N, ou seja, uma leitura não intersectiva. A leitura intersectiva (em (42): é violinista e é bom como pessoa) é alcançada com um pouco mais de facilidade com o diminutivo, que ainda mantém a leitura não intersectiva como uma opção. Mesmo o uso do superlativo ou advérbio mais adjetivo 
muitas vezes não é suficiente para marcar a leitura intersectiva. A presença deste adjetivo na classe dos exclusivamente pré-nominais, portanto, é discutível ${ }^{9}$. Defenderemos que são adjetivos qualificativos e que, na interpretação intersectiva, são adjetivos classificativos, pós-nominais. Ou seja, bom não é um adjetivo exclusivamente pré-nominal.
a. Um bom violinista
b. Um violinista bom
c. Um violinista bonzinho

Antigo, da mesma forma que bom, também possui na posição pós-nominal uma interpretação que não é encontrada na posição pré-nominal, que é a leitura de antigo como "velho"10. Mas há outra possibilidade interpretativa na posição pós-nominal, que seria a de uma mudança de referência com o tempo: um gerente antigo já não é mais gerente. A diferença é que, nestes casos, o adjetivo também pode ocorrer na posição pré-nominal: o antigo parque ${ }^{11}$. Este adjetivo seria, portanto, exclusivamente pós-nominal na leitura correspondente a "velho", e seria um adjetivo qualificativo que pode

${ }^{9}$ Um fato que parece contradizer esta proposta de que o adjetivo bom não pertence à classe dos exclusivamente pré-nominais é a possibilidade de redução deste adjetivo em línguas como o espanhol. A redução é considerada uma propriedade típica de categorias nucleares. Grande, por exemplo, um adjetivo exclusivamente pré-nominal, pode se reduzir a gran, como em un gran amigo (tradução do espanhol: um grande amigo), una mesa grande (tradução do espanhol: uma mesa grande). No caso do adjetivo bom, que defendemos que é gerado na posição pós-nominal sempre, também pode se reduzir a buen, como em muy buen amigo (muito bom amigo), un amigo muy bueno (um amigo muito bom). Se o critério da redução estiver correto, temos uma contraevidência para nossa proposta de que o adjetivo bom não pode ser considerado um núcleo pré-nominal. Não descartamos a possibilidade, contudo, de que haja comportamentos diferentes em Português e Espanhol.

${ }^{10}$ Esta leitura é possível na posição pré-nominal se estiver na forma superlativa ou se modificado por advérbio de grau elevado: o mais antigo filme/ o antiguíssimo filme de Charles Chaplin, O Grande Ditador.

${ }^{11}$ Há mais a se discutir aqui, visto que não está bem claro o contraste: um antigo gerente/ um gerente antigo; um antigo parque / *um parque antigo (com a leitura de que não é mais parque). Deixaremos este ponto em aberto. 
subir para a posição pré-nominal quando significa "que existiu em outro tempo".

(43) a. Antigo gerente (não é mais gerente)

b. gerente antigo (não é mais gerente)

(44) a. Antigo parque (não é mais parque)

b. parque antigo (velho)

Pequeno também possui uma interpretação na posição pós-nominal, a de algo mesquinho, que não é alcançada na posição anteposta ao nome. Nesta leitura, o adjetivo é exclusivamente pós-nominal. Na interpretação como algo de tamanho reduzido, o adjetivo pode ocupar as posições pré e pós-nominal.

(45) a. Atitudes pequenas (mesquinhas)

b. Pequenas atitudes (= de tamanho pequeno)

(46) a. Porção pequena de comida

b. Pequena porção de comida

Com o adjetivo novo, ocorre o mesmo: a interpretação "pouca idade" só está disponível quando o adjetivo segue o nome. Na posição pré e pós-nominal o adjetivo pode ter interpretação de "pouco tempo".

a. Um novo físico

b. Um físico novo

Diferentemente dos anteriores, que ocorrem na posição pré-nominal por resultado de movimento da posição posposta ao nome para uma posição mais alta que o nome, o adjetivo velho possui na posição pré-nominal a interpretação de "antigo numa situação ou função" que não está disponível para o adjetivo posposto ao nome. Na posição pós-nominal, o adjetivo pode significar “muito tempo de vida”, e esta opção tampouco está disponível na posição pré-nominal. 
(48) Um lindo prédio velho

(49) Um velho morador do prédio

Simples, assim como velho, também possui leituras diferentes em posições diferentes. A leitura da posição pré-nominal corresponde à leitura de mero, e, na posição pós-nominal, corresponde a algo não sofisticado, singelo, elementar.

(50) Um simples comentário

(51) Uma canção simples

Por fim, o adjetivo grande possui uma interpretação na posição anteposta ao nome que não é alcançada na posição pós-nominal, que seria a interpretação de algo importante, notável, de muitas qualidades. Já na interpretação como algo que tem dimensões maiores que o normal, ou que seja numeroso, o adjetivo pode se mover para a posição pré-nominal sob condições específicas.

(52) a. Grande compromisso (importante)

b. Grandes princípios da física (importante)

c. Uma grande experiência (importante)

a. Uma grande passeata (tinha muita gente)

b. Uma passeata grande (Maior que o normal, numeroso...)

Não deixa de ser curioso que o adjetivo grande, um exclusivamente pré-nominal, também ocorra em posição pré-nominal com a mesma leitura da pós-nominal, ou seja, como um qualificativo. Nenhum outro adjetivo exclusivamente pré-nominal listado aqui possui esta mesma característica.

Em resumo, os adjetivos velho, grande, pobre, certo e simples podem ser considerados exclusivamente pré-nominais, porque possuem leituras que só estão disponíveis nesta posição; a ocorrência destes adjetivos na posição pós-nominal explica-se por segunda entrada lexical. Já bom, antigo, pequeno e novo ocorrem na posição pré-nominal por movimento do $\mathrm{AP}_{\text {qualificativo }}$. As 
características morfossintáticas desta classe listadas anteriormente ${ }^{12}$ confirmam a asserção.

\begin{tabular}{|c|c|c|}
\hline & $\begin{array}{l}\text { EXCLUSIVAMENTE } \\
\text { PRÉ-N }\end{array}$ & $\begin{array}{l}\text { QUALIFICATIVO } \\
\text { PRÉ-N }\end{array}$ \\
\hline & $\begin{array}{l}\text { Velho, grande, pobre, certo, } \\
\text { simples }\end{array}$ & $\begin{array}{l}\text { bom, antigo, pequeno, } \\
\text { novo }\end{array}$ \\
\hline $\begin{array}{l}\text { Ser modificado } \\
\text { pelo advérbio } \\
\text { muito }\end{array}$ & $\begin{array}{l}\text { *Um muito velho morador } \\
\text { do prédio (forçando a } \\
\text { interpretação, seria a de } \\
\text { alguém de idade avançada, } \\
\text { leitura da posição } \\
\text { pós-nominal) }\end{array}$ & $\begin{array}{l}\text { Um muito bom violinista } \\
\text { (bom como violinista) }\end{array}$ \\
\hline $\begin{array}{l}\text { Aparecer na forma } \\
\text { superlativa }\end{array}$ & $\begin{array}{l}\text { ?O certíssimo momento } \\
\text { para ocorrer o casamento } \\
\text { (forçando a interpretação, } \\
\text { teríamos a leitura da posição } \\
\text { pós-nominal) }\end{array}$ & $\begin{array}{l}\text { Pequeníssimas porções } \\
\text { de carne para cada um } \\
\text { (quantidade reduzida) }\end{array}$ \\
\hline Nominalização & $\begin{array}{l}\text { *A simplicidade do } \\
\text { problema (não é possível } \\
\text { com a leitura de mero) } \\
\text { A pobreza do refugiado (só } \\
\text { pode significar pouco } \\
\text { dinheiro, que é a leitura da } \\
\text { posição pós-nominal) }\end{array}$ & A pequenez daquele ato \\
\hline Diminutivo & $* \mathrm{O}$ velhinho telefone & $\begin{array}{l}\text { Um antiguinho } \\
\text { problema que temos } \\
\text { A pequenina atitude que } \\
\text { mudou tudo }\end{array}$ \\
\hline Posição predicativa & $\begin{array}{l}\text { O refugiado é pobre (só tem } \\
\text { leitura pós-nominal: pouco } \\
\text { dinheiro) }\end{array}$ & $\mathrm{O}$ violinista é bom. \\
\hline
\end{tabular}

12 A discussão neste ponto é se estes adjetivos são qualificativos ou exclusivamente pré-nominais. A crítica que fizemos a Bernstein anteriormente, de que estas propriedades também se aplicam aos exclusivamente pós-nominais (adjetivos relacionais), não inviabiliza a discussão, visto que não há dúvida de que estes adjetivos não sejam relacionais, mas sim qualificativos. 
O fato de exclusivamente pré-nominais não ocorrerem em posição predicativa é coerente com a impossibilidade de estes adjetivos não ocorrerem fora do DP, como nas Small Clauses que seguem.
(54) *mero, esse problema
(55) * suposto, esse assassino
(56) *pretenso, o violinista

Isto também evidencia que pobre, certo, velho, grande e simples sejam adjetivos pertencentes ao grupo dos exclusivamente pré-nominais, pois possuem exatamente o mesmo comportamento.

(57) *pobre, o rapaz (só tem a leitura da posição pós-nominal: sem dinheiro) (58) *certo esse momento (só tem a leitura da posição pós-nominal: correto) (59) *velho, esse amigo (só tem a leitura da posição pós-nominal: muito tempo de vida)

(60) *grande, essa passeata (só tem a leitura da posição pós-nominal: numeroso)

(61) *simples, essa canção (só tem a leitura da posição pós-nominal: singelo)

Já bom, antigo, pequeno e novo não sofrem esta mesma restrição. São adjetivos que variam o posicionamento, podendo, inclusive, ocorrer numa posição mais alta que o DP, da mesma forma que inteligente e maravilhosa, adjetivos claramente qualificativos.

(62) Inteligente, o seu amigo

(63) Maravilhosa, a promoção

(64) Bom, o seu violinista

(65) Antigo, esse problema

(66) Pequena, essa porção de fritas

(67) Nova, essa desculpa

Uma outra evidência de que velho, grande, pobre, certo e simples são exclusivamente pré-nominais é o fato de terem vocábulos diferentes em 
outras línguas, uma para cada significado que a palavra possui ${ }^{13}$ :

(68) Velho Húngaro

a. egy nagyon öreg ember

um homem muito velho

b. a régi piros ház

a velha casa vermelha

(69) Grande Inglês

a. A great new

Uma grande notícia

b. A big building

Um edifício grande

(70) Pobre

Basco
a. ama gaixoa!
Pobre mãe!
b. Etxe pobrea
Casa pobre

(71) Certo

Inglês
a. Certain things

Certas coisas

b. The right thing

A coisa certa

(72) Simples

Basco

a. ogia egiteko modu erraza.

Um modo simples de fazer pão

b. langile soila baino ez naiz

Sou um simples trabalhador

${ }^{13}$ Podemos pensar que pequeno seria um problema nesse caso, pois em inglês temos também duas palavras, uma para cada significado: little e small. Este último contém uma noção de pequeno em tamanho e em importância, que little não contém. O significado de small corresponde ao adjetivo pequeno exclusivamente pós-nominal em PB, e little corresponde ao qualificativo pré e pós-nominal. 
A seguir, apresentaremos uma proposta de estrutura para os adjetivos, de forma que as diferenças apontadas anteriormente sejam predizíveis.

\section{A Estrutura dos Adjetivos Exclusivamente Pré-Nominais}

Com base nas informações apresentadas anteriormente, buscaremos apresentar uma proposta da posição em que é gerado o adjetivo exclusivamente pré-nominal. Por um lado, eles não são selecionados pelo nome, o que nos faz crer que estes adjetivos não sejam concatenados em SpecNP nem que sejam gerados na posição pós-nominal. Também não temos razões para defender que sejam gerados em NumP, visto que estes adjetivos também ocorrem em nomes de massa (cf. (73)), que não possuem projeção de número.

(73) Vou preparar um simples arroz com brócolis e cada um prepara a sua carne.

Não temos da mesma forma razões para defender que sejam gerados em DP, visto que tampouco têm relação com a definitude ou a especificidade do DP.

Apesar dos problemas já citados, vamos adotar uma proposta similar à de Bernstein e considerar que estes adjetivos sejam núcleos (ou seja, os adjetivos exclusivamente pré-nominais) e estejam hospedados abaixo de NumP ${ }^{14}$ e acima de NP. Assumir que estes adjetivos sejam núcleos tem como consequência a necessidade de explicar o que se passa quando este adjetivo não está presente, visto que ele se configura como um selecionador de NP. Vamos defender que NumP é capaz de selecionar tanto AP quanto NP. No caso de NumP selecionar um adjetivo exclusivamente pré-nominal, o nome surge como uma seleção do adjetivo.

${ }^{14}$ A projeção de Número é gerada por razões independentes ao adjetivo. 
(74)

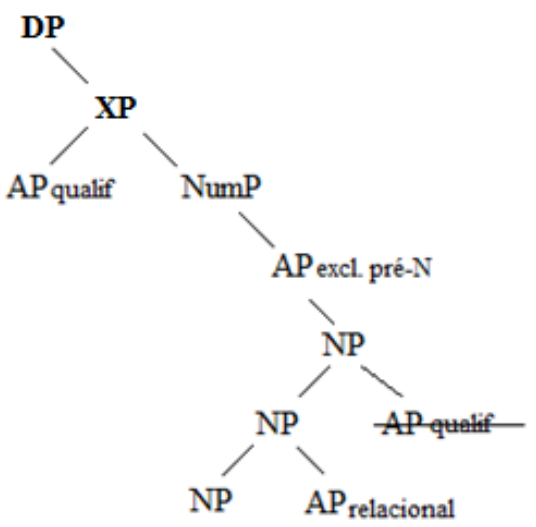

Esta estrutura consegue predizer a diferença de comportamentos dos adjetivos em NPs, já que todos os adjetivos, com exceção dos exclusivamente pré-nominais, são gerados sob NP, e consegue explicar por que os exclusivamente pré-nominais não têm seu significado dependente do nome que o sucede - é o adjetivo que seleciona o nome, nestes casos.

\section{Conclusões}

Buscamos entender, nesse trabalho, por que existem adjetivos exclusivamente pré-nominais em português, uma língua em que os adjetivos, grosso modo, tendem a ser pós-nominais. Duas propriedades se destacaram, que é o fato de os adjetivos exclusivamente pré-nominais não ocorrerem em NPs, mas apenas em DPs do português - o que mostra que possivelmente são gerados numa posição mais alta que o nome -, e que seu significado é independente do nome que o acompanha, ou seja, que estes adjetivos não são selecionados pelo nome, ao contrário, o selecionam sintaticamente. Estas características são exclusivas destes adjetivos, e acabam por nos fazer repensar numa diferenciação de posicionamento destes adjetivos na estrutura sintática em relação aos outros adjetivos. 


\section{Referências}

ABNEY, S. The English Noun Phrase in its sentential aspect. PhD Dissertation. Cambridge: MIT, 1987.

BERNSTEIN, J. Topics in the syntax of nominal structure across romance. $\mathrm{PhD}$ Dissertation. New York: CUNY, 1993.

BONET, E. Variation in the exponence of determiners and other prenominal elements. In: WORKSHOP ON SYNTACTIC VARIATION IN CATALAN AND SPANISH, 2013, Barcelona. Handout. Barcelona: CLT/UAB, 26-28 de junho de 2013.

BORGES NETO, J. O adjetivo e a construção do sintagma nominal: alguns problemas. Letras, Curitiba, n. 34, p. 28-38, 1995.

BOSQUE, I. Sobre las diferencias entre los adjetivos relacionales y los calificativos. Revista Argentina de Linguistic, v. 9, n. 1-2, p. 9-48, 1993.

BOSQUE, I. Adjective position and the interpretation of indefinites. In: GUTIERREZ-REXACH, J.; SILVA-VILAR, L. (Ed). Current issues in Spanish Syntax and Semantics. Studies in generative grammar. 53. ed. Berlim; New York: Mouton de Gruyter, 2001.

BOSQUE, I.; PICALLO, C. Postnominal adjectives in Spanish DPs. Linguistics, v. 32, p. 349-385, 1996.

CINQUE, G. On the evidence for partial N-movement in the Romance DP. Working Papers in Linguistics, 3.2. Paper. University of Venice: Centro Linguistico Interfaculta, 1993. p. 21-40. Disponível em: <http://bit.do/bGRAg>. Acesso em: 24 jun. 2013.

CINQUE, G. The syntax of adjectives: a comparative study. Cambridge, MA: MIT Press, 2010. (Linguistic Inquiry Monograph Fifty-Seven).

CYRINO, S.; ESPINAL, M. T. Bare nominals in BP: more on the DP/ NP analysis. Natural Language and Linguistic Theory, Sep. 2014. [no prelo]. 
CORNILESCU, A.; DINU, A. Adjectives and specificity. RRL, București, v. 58 , n. 4 , p. $455-480,2013$.

CRISMA, P. Functional categories inside the noun phrase: a study on the distribution of nominal modifiers. 1990. Tese. University of Venice.

CRISMA, P. On adjective placement in Romance and Germanic event nominals. Rivista di Grammatica Generativa, v. 18, p. 61-100, 1993. Disponível em: <http://bit.do/bGRAw>. Acesso em: 16 jan. 2009.

CRISMA, P. On the configurational nature of adjectival modification. In: ZAGONA, K. (Ed). Grammatical Theory and Romance Languages Amsterdam, Philadelphia: John Benjamins, 1996. (Current Issues in Linguistic Theory, n. 133).

DEMONTE, V. A minimal account of Spanish Adjective position and interpretation. In: FRANCO, J. A.; LANDA, A.; MARTIN, J. (Eds). Grammatical analyses in Basque and Romance Linguistics. Amsterdam; Philadelphia: John Benjamins, 1999. (Current Issues in Linguistic Theory, n. 187).

DEMONTE, V. Meaning-form correlations and adjective position in Spanish. In: McNALLY, L.; KENNEDY, C. Adjectives and adverbs. UK: Oxford University Press, 2008. p. 71-100.

DEMONTE, V. Semantics of adjectives and adverb(ial)s. In: MAIENBORN, C.; VON HEUSINGER, K.; PORTNER, P. (Eds.). Semantics: an international handbook of natural language meaning. Berlim; Boston: Walter de Gruyter GmbH \& Co, 2011. p. 1314-1340.

DONATI, C.; CECHETTO, C. Nouns do not take complements: A theoretical claim and a psycolinguistic experiment. The Proceedings of the Fourteenth Tokyo Conference on Psycholinguistics (TCP2013). 2013.

ERNST, T. The syntax of adjuncts. Cambridge: Cambridge University Press, 2004. (Cambridge Studies in Linguistics, 96).

ESPINAL, M. T; McNALLY, L. Bare nominals and incorporating verbs in Catalan and Spanish. Journal of Linguistics, v. 47, p. 87-128, 2011. 
GIORGI, A.; LONGOBARDI, G. The syntax of Noun Phrase:

Configuration, parameters and empty categories. Studies in Language, v. 16, n. 1, p. 201-205, 1992.

KAYNE, R. The antisymmetry of syntax. Cambridge, MA: MIT Press, 1994.

LAMARCHE, J. Problems for N-movement to NumP. Probus, v. 3, p. 215-236, 1991.

LARSON, R. Olga is a beautiful dancer. LSA, New Orleans, Jan. 1995. Disponível em <http://bit.do/bGRBw>. Acesso em: 1 set. 2012.

LARSON, R. Events and modifications in Nominals. In: STROLOVITCH, D.; LAWSON, A. (Eds.). SALT, Ithaca, NY, v. 8, p. 145-168, 1998. Disponível em: <http://bit.do/bGRBr>. Acesso em: 1 set. 2012.

LEMLE, M. A ordem dos adjetivos no sintagma nominal inglês: implicações para a teoria gramatical. In: ENCONTRO NACIONAL DE LINGUÍSTICA, 3., 1979, Rio de Janeiro. Apresentação de trabalho.

LONGOBARDI, G. Reference and proper names: A theory of N-Movement in syntax and logical form. Linguistic Inquiry, v. 25, n. 4, p. 609-665, Aut. 1994.

McNALLY, L.; BOLEDA, G. Relational adjectives as properties of kinds. In: BONAMI, O.; HOFHERR, P. C. (Eds.). Empirical Issues in Syntax and Semantics, v. 5, p. 179-196, 2004. Disponível em:

<http://bit.do/bGRBG>. Acesso em: 20 out. 2012.

MENUZZI, S. Adjectival positions inside DP. In: CREMMERS, C.; BOK-BENEMA, R. (Eds.). Linguistics in the Netherlands. Amsterdam: John Benjamins, 1994. p. 127-138.

PICALLO, C. A mark of specificity in indefinite nominal. Catalan Working Papers in Linguistics, Universitat Autònoma de Barcelona, v. 4, n. 1, p. 143-167, 1994. Disponível em: <http://bit.do/bGRBN>. Acesso em: 13 maio 2014. 
RIZZI, L. The fine structure of the left periphery. In: HAEGEMAN, L. (Ed.). Elements of Grammar. Dordrecht: Kluwer, 1997. p. 281-337.

RIZZI, L. Relativized minimality. Cambridge, MA: MIT Press, 1990. [Linguistic inquiry monographs, 16].

Recebido em: 01/05/2015

Aceito: 17/10/2015 